\title{
Trajetórias e tempos das traduçōes de Alexandre Dumas em Portugal e no Brasill
}

Trajectories and times of Dumas' translations in Portugal and in Brazil

\author{
Maria Lúcia Dias Mendes
}

Universidade Federal de São Paulo, campus Guarulhos, SP, Brasil

\begin{abstract}
Resumo: 0 artigo examina a trajetória de Alexandre Dumas na França comparando-a com sua recepção em Portugal e no Brasil. A partir daí, discute os tempos e os suportes das publicações das traduções nos dois países em relação às edições francesas. Conclui-se que, apesar da proximidade entre a França e Portugal, as traduções brasileiras priorizavam o jornal como suporte e eram, na maioria, feitas em menos tempo do que as portuguesas.

Palavras-chave: Alexandre Dumas. Tradução. Recepção.
\end{abstract}

Abstract: The article examines the literary career of Alexandre Dumas in France and compares it to the reception of his work in Portugal and in Brazil. It also discusses the different print materials and times of publication of the translations of his work in both countries in comparison to the French editions. One can conclude that, despite the proximity of France to Portugal, the translations in Brazil were mostly published in newspapers and came out before the Portuguese ones.

Keywords: Alexandre Dumas. Translation. Reception.

1 Os resultados parciais desta pesquisa foram apresentados no Colóquio "A Circulação Transatlântica de Impressos: Conexões", durante o período de 27 a 29 de agosto de 2012, na Universidade de São Paulo; a pesquisa vem sendo desenvolvida com auxílio da Fapesp, como parte do Projeto Temático "Circulação Transatlântica dos Impressos". 
S'il existe en ce moment, disait-on en 1850, dans quelque île desérte, un Robinson Crusoé, il est en train de lire Les trois mousquetaires.

(André Maurois, Les trois Dumas).

Maria Lúcia

Dias Mendes

136

Dizer que o público contemporâneo de Alexandre Dumas aclamou suas obras em vários países já se tornou um truísmo. Basta acompanhar as edições que circularam à época, nos anúncios de livreiros nos jornais, nos catálogos de bibliotecas e gabinetes de leitura, no repertório das companhias teatrais, nas memórias de leitores e críticos, para percebermos que Dumas teve suas obras lidas e representadas tanto em francês quanto em traduções pelas quatro partes do mundo. Entretanto, tanto o percurso quanto o suporte em que essas obras circulavam ainda não nos são claros.

Um dos objetivos da pesquisa sobre a obra de Alexandre Dumas no Brasil é organizar as informações sobre as traduções feitas durante o século XIX, de modo a compreender de que forma se deu a recepção dos folhetins em relação à simultaneidade de versões oferecidas aos leitores: aquelas publicadas em francês (no jornal, em livro, contrafações belgas) ou em português (publicadas em jornais portugueses, brasileiros, em livros editados no Brasil ou em Portugal).

As perguntas que norteiam a pesquisa são: Como essas obras teriam chegado ao Brasil? Qual teria sido o tempo entre a publicação na França e no Brasil? Portugal teria sido um intermediário na trajetória dessas obras?

Assim, o primeiro passo foi tentar organizar uma cronologia das publicações na França, em Portugal e no Brasil. Depois, procurei comparar os tempos entre a publicação das obras em Paris, no Brasil e em Portugal, para perceber se o hiato se fazia presente ou não, se havia a possibilidade de a tradução portuguesa ter chegado às mãos dos leitores brasileiros antes da tradução feita aqui.

Neste artigo, discuto apontamentos da pesquisa em andamento, ainda um trabalho sem conclusão. Tratarei do início da carreira de Alexandre Dumas na França e a sua entrada em Portugal e no Brasil, para dar a conhecer um pouco do percurso desse autor. Depois comento alguns dados apresentados nos dois anexos deste artigo: o Anexo A compara as publicações de Dumas na França e suas respectivas traduções em Portugal e no Brasil, e o Anexo B traz apenas publicações francesas 
e suas traduções brasileiras. No final, veremos que há concomitância de obras em francês e português circulando no Brasil.

\section{Alexandre Dumas dramaturgo, só depois romancista}

Desde o final do século XVIII, Paris atraía jovens que desejavam viver de Trajetórias literatura. Além de seus sonhos de consagração, Alexandre Dumas, naquele e tempos das ano de 1823, traz de sua pequena cidade natal, Villiers-Cottêrets, alguns esboços de vaudevilles, escritos com seu amigo Adolphe de Leuwen, e alguns poemas. A poesia e o teatro eram, na França da época, os gêneros mais propícios à consagração literária, e Dumas neles aposta, desde o início.

Dumas perseguiu a poesia por alguns anos, publicando poemas traduções de Alexandre

Dumas em Portugal e no Brasil que ficaram esquecidos em revistas literárias do seu tempo, e pouco a pouco foi desistindo desse gênero. A morte do amigo de seu pai e seu protetor, Maximilien Sébastien Foy, lhe propiciou o tema para a "Élegieau Général Foy", composta em 1825 como homenagem àquele que lhe conseguiu um emprego como secretário do Duc d'Orléans. Essa elegia, impressa pelo autor e distribuída durante os rituais do funeral, alcançou um certo sucesso e foi posteriormente publicada no recém-criado jornal Le Figaro (15 de fevereiro de 1826). Mas Dumas não era exatamente dotado para a poesia e esse talvez tenha sido o primeiro e único momento em que foi reconhecido como poeta.

Quanto ao teatro, é no palco do Théâtre de la Porte Saint-Martin que Dumas vai encenar suas primeiras criações, feitas a quatro mãos com seu amigo Adolphe de Leuwen: La chasse et l'amour (1825) e La noce et l'enterrement (1826). Os dois vaudevilles não trouxeram quase nada de dinheiro e muito menos o tão aguardado sucesso. São lembrados por registrarem na História o fato de serem as únicas obras assinadas por Dumas como Alex Davy, nome que remete à ascendência nobre da família de seu pai, Davy de la Pailleterie, que ele fez questão de ter em seus documentos, mas nunca mais usou.

Em meio a poesias, vaudevilles e muita leitura dos clássicos e contemporâneos - como Shakespeare, Racine, Schiller, Walter Scott, entre outros -, Dumas aventurava-se também em outro gênero, a novela. Em 1826, publica três novelas ("Laurette", "Blanche de Baeulieu" e "Marie") reunidas com o título de Nouvelles contemporaines, pela editora Sétier.

Mas o sucesso e o reconhecimento só vieram após a primeira representação de Henri III etsacour, em 1828, um drama histórico em cinco atos escrito em prosa que, ao romper completamente com as regras 
Maria Lúcia

Dias Mendes

do teatro clássico no palco da Comédie-Française, alça em apenas duas horas Alexandre Dumas do anonimato à condição de célebre autor dramático. Esse grande sucesso de Dumas - encenado 152 vezes até 1895, quando foi retirado do repertório - abriu caminho para outros, não menos inovadores, representados principalmente no Théâtre Porte-Saint-Martin que, à época, acolheu grande parte dos dramas românticos.

As obras teatrais de Dumas provocaram amores e ódios, críticas avassaladoras, elogios apaixonados e muitas polêmicas, movidas tanto pelo que era apresentado surscène (temas, desenlaces, performance dos atores) quanto pelo que acontecia nos bastidores (problemas com a censura da Comédie-Française, apropriação de temas já tratados em outras obras, coautorias não declaradas, acusações de plágio, escândalos pessoais, entre outros). 0 drama romântico dumasiano transbordava do teatro, tomava espaço nos salões, nos cafés, nos gabinetes dos políticos e censores, nos jornais. Alexandre Dumas tornou-se uma celebridade.

Os sucessos inesquecíveis de cena foram: Antony (1831) arrebatou a plateia com a representação pungente de uma paixão contemporânea, capaz de levar ao sacrifício da morte o casal que não pode confrontar a sociedade por seu amor; La Tour de Nesle (1832) reescreve a terrível história (já tratada em um melodrama de Gaillardet) da rainha Marguerite de Bourgogne, que, ao final da orgia, atirava seus amantes da torre às margens do Sena, a fim de que eles não a reconhecessem no dia seguinte; Christine ou Stockholm, Fontaine bleau et Rome (1831); Napoléon Bonaparte ou Trent ans d'Histoire de France (1830); Charles VII chez ses grands vassaux (1831); Richard Darlington (1831); Teresa (1832); Le mari de laveuve (1832); Le fils de l'èmigré (1832); Angèle (1833); Catherine Howard (1834), entre outros.

Mesmo com o sucesso teatral, Dumas ainda mantém o caminho que era percorrido pela maioria dos aspirantes a escritores, desejosos de viver de sua pluma: escrever para periódicos (THÉRENTY, 2007). Alimentado pelos textos de jovens sequiosos por um ganha-pão, o jornal e as revistas permitiam tanto a subsistência do autor quanto seus exercícios criativos, e, assim como outros, Dumas vai se servir do sucesso mediático (e financeiro) do jornal para experimentar outros gêneros: dedica-se a escrever récits de voyages, narrativas autobiográficas e novelas, sobretudo de temas históricos, inspiradas na obra de Walter Scott e nas Histoires du Ducs de Borgogne, de Proper de Barante. Esses textos curtos, escritos como causeries, em um estilo informal que lhe é bem peculiar, 
são publicados em revistas e jornais parisienses (Revue des Deux Mondes, Mercure de France, Le Moniteur, Psyché, Le Musée des Familles), garantindo ao autor algum dinheiro.

Depois de uma temporada viajando pela Itália entre 1834 e 1835, Dumas parece ter perdido o seu dom para os dramas; as obras que trouTrajetórias xe na sua bagagem não alcançaram a repercussão esperada, restava-lhe o feuilleton da Revue des Deux Mondes, no qual misturava crítica teatral, récits de voyages e causeries. 0 romantismo parecia já ter se exaurido, faltava-lhe fôlego para reacender os ânimos dos parisienses, que já estavam à espera de outras emoções fortes. Era necessário que Dumas se reinventasse.

A criação de La Presse em 1836 vai consolidar definitivamente a ligação de Alexandre Dumas com as publicações em periódicos. Émile e tempos das traduções de Alexandre

Dumas em Portugal e no Brasil de Girardin pede ao autor teatral, agora enveredando pela crítica, que escreva comentários de todas as apresentações feitas nos teatros Porte-Sainte-Martin e Théâtre Français e que mantenha o jornal atualizado trazendo as principais questões em debate na "littérature dramatique". Além disso, Dumas poderá escrever sobre política, se desejar, e Girardin promete reservar o feuilleton de domingo para que o amigo publique suas narrativas sobre os reinados mais importantes da história da França. As condições financeiras são interessantes: a linha valia 1 franco nos artigos e 1,25 franco nos feuilletons, além de um camarote reservado para as premières dos dois teatros, pago pelo jornal. Estimulado pela nova concepção de jornal que Girardin criou, nasce Alexandre Dumas jornalista, ocupando no jornal La Presse o lugar prestigioso (e odiado) de crítico dos espetáculos que representam a produção contemporânea, e, em seus feuilletons dramatiques, comenta e expõe suas ideias sobre a arte e a política artística do seu tempo.

o feuilleton do domingo abrirá um outro espaço para a imaginação de Dumas. Será chamado de Scènes Historiques e tornar-se-á um lugar de reflexão e experiências da narrativa, sua estrutura e as suas relações com a História, permitindo-lhe formular esse gênero que, segundo ele, estaria entre o romance e o drama, e cujo tema histórico traria o interesse provocado pela narrativa unido à força dramática do diálogo. Como o autor escreve em suas memórias, logo percebeu como isso deveria ser feito: "Com minha aptidão já bem determinada para o teatro eu me pus a recortar, a narrar e colocar em diálogos as cenas históricas 
Maria Lúcia

Dias Mendes

retiradas da Histoire des ducs de Bourgogne."2 (DUMAS, 1989, p. 696, tradução nossa). Essas cenas históricas, no início curtas dramatizações de episódios, vão pouco a pouco deixando mais espaço à ficção, ao romance. $\mathrm{O}$ público aprova, as assinaturas do jornal aumentam, e logo Dumas publica suas scènes em volume, com o título de Chroniques de France.

Apesar do sucesso que suas novas incursões nas páginas dos jornais propiciam, Dumas continuava apresentando suas peças aos comitês dos teatros de Paris, desejando recuperar a glória que, à época, só os palcos podiam dar a um autor. Algumas obras são aceitas, mas não atingem o sucesso desejado.

Em meio a todas essas veredas abertas, surge um convite de Le Siècle, concorrente direto do jornal em que escrevia, pedindo que Dumas lhe forneça uma narrativa para ser publicada imediatamente. Assim, Le capitaine Paul, um drama escrito durante a sua viagem à Calábria em um período em que foi obrigado a ficar dentro do barco nas costas do Mediterrâneo por conta de uma calmaria (e que não havia sido aceito para ser representado em nenhum teatro), torna-se um romance. $\mathrm{O}$ primeiro romance escrito para ser publicado em formato de folhetim, em fatias.

$O$ escritor escolhe a forma romanesca porque é aquela que vende. $O$ teatro continua sendo o gênero nobre, mas que não lhe garante mais o dinheiro necessário para viver. Dumas segue o gosto do tempo e parece às vezes conseguir intuí-lo antes mesmo do seu público e de seus intermediários. Alexandre Dumas romancista, assim como o jornalista, nasce da necessidade.

A trajetória de Alexandre Dumas não segue, absolutamente, um projeto literário organizado. Vai ao sabor do vento, seguindo as modas e os desejos de seu tempo - e suas necessidades financeiras. Ao chegar a Paris, vislumbra a possibilidade do sucesso nos palcos e lá se realiza. Depois, na impossibilidade de se manter como chef de file, envereda-se no jornal, suporte que lhe oferece um espaço para discussão do seu fazer teatral e para suas inovações na narrativa. Experimenta as escrituras do eu, as causeries, flerta com a História. Daí, para o romance, um pulo. Sem deixar de lado as outras ambições literárias, os outros gêneros que já domina, Dumas se apropria da

2 "Avec mon aptitude déjà bien décidée au théâtre, je me mis à découper, à raconter et à dialoguer des scènes historiques tirées de l'Histoire des ducs de Bourgogne." 
forma do romance que, adaptável, lhe permite lançar mão do arsenal de ferramentas trazidas de suas outras experiências.

O romance-folhetim dumasiano nasce tanto do domínio das técnicas narrativas e teatrais quanto do desejo de agradar ao público (e, consequentemente, continuar sendo bem pago). Dumas descobre, graças às Trajetórias suas habilidades como dramaturgo, o essencial para a concepção de um romance-folhetim: ação, diálogos e o corte dos capítulos (les chutes de rideaux teatrais, que mantêm o suspense e a tensão até o próximo número e são usados como elemento de composição desse tipo de romance).

A estreita ligação entre o romance-folhetim, o melodrama e o drama romântico também aparece nos diálogos marcantes que colocam o leitor in media res; nas personagens que trazem em si contradições; nas descrições que remetem aos recursos cênicos; no uso da aventura e da e tempos das traduções de Alexandre

Dumas em Portugal e no Brasil peripécia para segurar a curiosidade do leitor até o próximo capítulo.

O estilo de Dumas, que se torna uma griffe, é a mistura de influências vindas das estéticas contemporâneas de sucesso somadas às suas características pessoais: desenvoltura para narrar histórias, criatividade para compor as cenas e criar peripécias. Nas palavras do escritor, o que o diferenciava dos seus companheiros de geração era a sua capacidade de vulgarizar, ou melhor, divulgar em uma linguagem acessível as ideias românticas.

Alexandre Dumas chegou a Portugal pelo Teatro da Rua dos Condes. Em francês. Encenado pela companhia francesa de Émile Doux, responsável pela introdução do drama romântico em Portugal (SANTOS, 2008), de janeiro de 1835 a abril de 1837, foi aos poucos ganhando traduções mais ou menos apressadas, que não diminuíam em nada o sucesso que as apresentações provocavam até 1840 . Depois foi de teatro em teatro até chegar ao Ginásio, aberto em 1846.

Os sucessos de Dumas formavam tanto os autores e atores da geração romântica portuguesa quanto o gosto do público que, como seus contemporâneos franceses, aplaudiu Antony (1831), Richard Darlington (1831), La Tour de Nesle (1832) e Catherine de Howard (1834), dramas representados apenas entre 1838 e 1839, não sem provocar comentários inflamados e muitas vezes indignados entre os críticos. Em seguida, os dramas eram publicados no Archivo Theatral ou Collecão selecta dos mais modernos dramas do teatro francês ou em jornais ou revistas (desde o final da década de 1830, circulavam em Portugal cerca de quarenta revistas consagradas ao teatro) (FRANÇA, 2003). 
Na corte brasileira, os dramas românticos de Dumas eram representados no Theatro São Pedro e no Theatro Nitheroyense, anunciados no Jornal do Commercio. No dia 5 de dezembro de 1838, por exemplo, foi apresentado em noite de gala o drama La Tour de Nesle, em comemoração ao aniversário de D. Pedro II. Os dramas românticos de Dumas foram, assim como os de Victor Hugo, vistos pelos autores brasileiros e provocaram criações nacionais, performances românticas e críticas na imprensa da época. Parece que a publicação dos dramas no Brasil não era um hábito, pois encontrei até o momento apenas uma referência sobre uma peça

Maria Lúcia

Dias Mendes publicada na época (Le Comte Hermann, de 1849, o Conde Hermano, 1852).

Assim como em seu país de origem, Dumas inicia a sua carreira de sucesso em terras portuguesas e brasileiras como dramaturgo. Contudo, é o romance que irá consolidar esse percurso.

Nesse período, a partir da década de 1830, parece que a febre do romance havia chegado às terras lusófonas. Tanto no Brasil quanto em Portugal o público leitor estava ávido pelas narrativas, interessado em descobrir esse gênero meio bastardo que se adaptava tão bem às suas novas inquietações e seus novos interesses. A tradução de obras estrangeiras veio suprir de imediato esse anseio, tornando-se "um incentivo de primeira ordem, criando no público o hábito do romance e despertando o interesse dos autores" (CANDIDO, 2009, p. 440), autores que precisavam se afirmar diante de uma tradição local que não privilegiava a prosa de ficção e precisavam desbravar as suas próprias veredas.

Em Portugal, já na década de 1840, começam a serem traduzidas as narrativas de Dumas. Martin de Freytas, Paulina, Pascoal Bruno... Obras publicadas no final da década de 1830 em Paris que chegam aos leitores em português, preparando o caminho para o que seria o primeiro grande best-seller: Les Trois Mousquetaires (1844, traduzido em 1847-1848), em volume.

No período de 1840 a 1860, Portugal assiste a um grande aumento da publicação e do comércio de livros, em parte provocado pela difusão do romance. A partir dos anos de 1850 , começam as edições populares em Portugal (Biblioteca Econômica, Gabinete Literário, Biblioteca Popular) e nota-se um sensível aumento no número de títulos e de reimpressões (ROGRIGUES, 1992). O consumo era alimentado pela venda de obras estrangeiras, pois, segundo Sobreira, "Em geral, os editores preferiam investir em traduções de obras com êxito já comprovado no estrangeiro, e que, portanto, lhes davam garantias de obtenção de lucros, a apostar nos autores nacionais, o que obviamente implicava correr um risco 
financeiro maior." (SOBREIRA, 2011, p. 2). O aumento das publicações corresponderia mais à grande oferta das traduções dos títulos franceses do que à produção de autores portugueses.

No Brasil, esse período marca o início das atividades da Typographia Paula Brito na impressão de obras literárias estrangeiras, muitas vezes traduzidas por ele mesmo, de autores franceses consagrados na época, entre eles Alexandre Dumas. Entretanto, seguindo Hallewell, apenas a partir da metade da década de 1860 , com a entrada efetiva do editor Baptiste-Louis Garnier no mercado de livros de ficção, é que tem início uma ampla produção de romances em forma de livro (HALLEWELL, 1985).

Assim como na França, aqui quem acolhe o romance é o jornal, no início fatiando os antigos sucessos, depois publicando romances-folhetins feitos sob medida para o espaço que lhes é reservado. Antes

Trajetórias e tempos das traduções de Alexandre

Dumas em Portugal e no Brasil mesmo de 1838, ano em que o Jornal do Commercio publica O Capitão Paulo, de Dumas, a narrativa já tinha seu espaço garantido, aumentando as vendas do jornal.

Segundo Ernesto Rodrigues (1998), desde 1836 alguns jornais portugueses começam a separar dentro da categoria Variedades, no rez-de-chaussée, o espaço dedicado à literatura do dedicado às variedades em geral, separar o romance-folhetim do folhetim-crônica. Entretanto, a palavra "folhetim" associada à "narrativa", ao espaço delimitado na página e encerrada com o famoso "Continuar-se-à" ao final do trecho, só aparece no jornal o Português (Lisboa, 14 de dezembro de 1840): "Folhetim. Portugal e os castelhanos em 1644." o folhetim tornou-se uma febre, publicando sobretudo traduções de autores franceses. Alexandre Dumas, Paul de Kock, Fréderic Soulié, Paul Féval são publicados em jornais de Lisboa e da província.

Apesar de os contextos históricos serem diferentes, tanto em Portugal quanto no Brasil a imagem de Alexandre Dumas, em um primeiro momento, foi a de um chef de file do drama romântico francês. Entretanto, foi a sua produção da década de 1840, mais voltada para o romance, a causerie e os récits de voyage, que garantiu o sucesso que ele havia conhecido na década anterior. Dos dois lados do Atlântico, o romance-folhetim foi fundamental para a difusão da obra de Dumas, consolidando o seu sucesso e aumentando as possibilidades de sua publicação.

Mas será que as publicações dessas obras seguiam esse percurso, que parece quase natural, de circulação dos impressos, isto é, saíam da França, passavam por Portugal e só depois chegavam ao Brasil? 
Maria Lúcia

Dias Mendes

\section{Publicações de Alexandre Dumas entre França, Portugal e Brasil}

As obras de Alexandre Dumas podem ser um bom parâmetro para que possamos descrever a circulação de impressos durante o século XIX. Autor de obras de vários gêneros, consagrado pelo público dos dois lados do Atlântico, tornou-se um best-seller de presença incontornável nos anúncios de livros à venda em jornais, nas listas de obras mais emprestadas e mais adquiridas pelas bibliotecas e gabinetes de leitura. Sucesso entre leitores portugueses e brasileiros, sua recepção teria acompanhado a mesma trajetória que teve na França?

Ao pensarmos no caminho percorrido pelas obras de Alexandre Dumas, pode parecer mais natural que o menor percurso geográfico tenha imperado, que o caminho tenha sido aquele da Europa para o Brasil (França-Portugal-Brasil), visto que Portugal já havia sido o intermediário na circulação dos impressos que entravam no Brasil antes da criação da Impressão Régia.

Examinei essa viagem feita pelas obras entre os três países, intermediada pela tradução, procurando compreendê-la como uma maneira de aclimatação em outras terras, em que o tempo e o suporte escolhido para a publicação já revelam uma espécie de "acomodação" dessas obras a um outro contexto.

Para abordar essas questões no caso das obras de Dumas, comparei 28 títulos (Anexo A) publicados durante o século XIX tanto em Portugal quanto no Brasil, com o intuito de depreender qual seria o percurso da tradução, qual foi o primeiro suporte e quanto tempo demorou para ser feita em relação à publicação francesa.

Entre esses 28 títulos, comparando as datas de publicação e o suporte tanto em Portugal como no Brasil, percebi que, em relação às datas de publicação na França, vinte obras haviam sido publicadas primeiro no Brasil e com a predominância do jornal; quatro haviam sido publicadas antes em Portugal e em volume e três haviam sido publicadas praticamente ao mesmo tempo em Portugal e no Brasil.

E ainda há uma obra, Martin de Freitas, publicada em 1835 na França, para a qual encontrei uma referência de publicação em Portugal em 1841 e um exemplar do mesmo ano no Real Gabinete Português de Leitura do Rio de Janeiro, que tendo a acreditar que seja da mesma edição. Entretanto, temos dois anúncios do mesmo título no Jornal do Commercio de 1840 , o que leva a pensar que poderia haver uma edição brasileira anterior à portuguesa, ainda não identificada. 
Esses dados da publicação da obra de Dumas em Portugal seguem o mesmo princípio observado em relação à publicação de outros autores franceses do mesmo período. Segundo Antonio Rodrigues, em A tradução em Portugal (1992), Victor Hugo, Paul Féval, Paul de Kock, Fréderic Soulié e mesmo Eugène Sue tiveram suas obras publicadas primeiro em volume e só depois em jornal.

Podemos pensar que a tradução das obras de Dumas em Portugal era feita depois de a obra sair em volume na França, ao passo que no Brasil era feita diretamente da publicação em jornal, assim que os exemplares chegavam.

O mercado livreiro em Portugal era em grande parte estimulado por editores franceses estabelecidos no país, que eram responsáveis pela circulação de obras para o público culto e popular. Até 1834, a

Trajetórias e tempos das traduções de Alexandre

Dumas em Portugal e no Brasil maioria dos títulos em circulação ainda era portuguesa, mas em 1836 as traduções atingem $56 \%$ das obras oferecidas; o equilíbrio só virá na década de 1840. "Editores e livreiros de origem francesa (Aillaud, Rollandiana), residentes em Portugal bem assim como intelectuais exilados (Garret, Herculano, entre outros) deram um contributo fundamental para a caracterização do mercado literário" (RIBEIRO, 1999, p. 205). Assim como outras partes do mundo, Portugal sucumbia à paixão pela literatura francesa.

No caso brasileiro, a opção pelo jornal parece atender ao imediatismo da publicação em folhetins: assim que chegavam de Paris, os romances eram traduzidos e impressos. Ao que parece, graças aos avanços da técnica, a imprensa teria se transformado em um veículo mais rápido e espontâneo, no qual as traduções feitas "no calor da hora" tinham espaço garantido. Nossos editores demoraram a investir na publicação dos romances-folhetins em volume, ao contrário da França, onde esse era o procedimento habitual desde o início. A reimpressão em volume foi adotada de maneira gradual e não contemplou todas as obras que haviam aparecido em folhetins (HALLEWELL, 1985, p. 141).

Um gênero que parece não ter atraído muito a atenção dos editores brasileiros foram os dramas: na França, após a consagração nos palcos, se seguia a publicação em volume. Mesmo em Portugal, temos alguns dramas de Dumas publicados pela Impressora da Universidade de Coimbra (Antony, Theresa). A única referência que encontrei de uma publicação brasileira dos dramas dumasianos foi um anúncio no jornal Diário do Rio de Janeiro de 14 de janeiro de 1839, que tratava do lança- 
Maria Lúcia

Dias Mendes

mento do quarto volume da Biblioteca Theatral Romântica do Brasil, que continha três obras de Alexandre Dumas: A justa subterrânea, 0 inglez extravagante e A consulta. Não encontrei na relação das obras de Dumas nenhum título que se aproxime ou que possa ter sido traduzido do francês da maneira que aparece nessa coletânea.

Entre as obras (entre romances, causeries, novelas) publicadas primeiro no Brasil, temos três obras que foram impressas com menos de seis meses de diferença do lançamento na França; uma obra foi publicada no intervalo de seis meses; três no intervalo de seis a 11 meses e, publicadas em um ano ou mais, 14 obras. A partir desses títulos pesquisados, posso afirmar que pouco tempo separa a publicação francesa da publicação brasileira das obras de Dumas, reforçando a ideia de que essas obras circulavam muito rapidamente entre a França e o Brasil e que não necessariamente passavam por Portugal. Por outro lado, é interessante notar que até o momento há uma consonância entre os títulos traduzidos nos dois países. Ainda não tenho uma lista extensa das obras de Dumas traduzidas no Brasil, mas parece-me que em Portugal foram feitas mais traduções do que aqui. Apesar disso, encontrei algumas obras traduzidas apenas no Brasil. Entre as 17 obras encontradas, 14 tiveram a sua primeira publicação em jornal; e, quanto ao intervalo no tempo de publicação em relação à França, três obras foram publicadas antes de três meses, uma obra menos de seis meses depois; duas obras entre seis e 11 meses da publicação francesa; e 11 depois de um ano ou mais do lançamento francês.

A grande quantidade de obras curtas (causeries, récits de voyage) escritas por Dumas favorece as publicações intermitentes e as edições em formato de coletânea, sobretudo no Brasil. Favorece, também, os arranjos que não obedecem à cronologia da produção. Muitas vezes é difícil localizar a obra original, pois a tradução traz apenas um trecho, um capítulo de um livro ou uma causerie, por exemplo, sem referências à obra da qual o trecho foi tirado.

Há, nos dois países lusófonos, o hábito de publicar separadamente capítulos de livros ou causeries que foram reunidas em coletânea (por terem um tema comum), como obra completa e sem fazer referência ao todo. Parece que o estilo dumasiano de escrever, o gosto pela causerie e a criação de um narrador que parece estar sempre em cena, conversando animadamente com o leitor, propiciaram recortes e, por consequência, edições diferentes. Duas causeries, cujo tema é uma viagem à Calábria, que originalmente saíram na Revue de Paris e foram editadas em um li- 
vro com outras da mesma época com o título de Speronare (Impressions de Voyage, Italie), foram publicadas separadamente em Portugal e no Brasil (Gaetano Sferra e La Chapelle Gothique).

Ou temos o caso de Pascal Bruno, uma novela histórica publicada na França em La Presse, que foi traduzida no Brasil para o Jornal do Commercio e que tem uma segunda edição em terras brasileiras publicada na companhia de novelas de autores de várias épocas, em livro. Ou ainda uma causerie intitulada Don Martyn de Freytas, que fazia parte do livro Souvenirs d'Antony, que foi publicada e fez sucesso como uma causerie independente, tanto no Brasil quanto em Portugal. O mosaico que é a obra de Dumas, um autor que nunca abre mão dos gêneros que domina, e o seu temperamento (que tudo quer abarcar) exigem do pesquisador alguma paciência e um pouco de sorte para encontrar as referências

Trajetórias e tempos das traduções de Alexandre

Dumas em Portugal e no Brasil corretas, pois mesmo na França foram muitas as edições, em suportes diferentes e em coletâneas, induzindo à confusão de datas e títulos.

Não encontrei referências no Brasil ou em Portugal sobre a tradução de nenhum texto mais, digamos assim, teórico produzido por Dumas. Não foram poucos os ensaios escritos por ele sobre questões relativas à estética romântica ou comentários críticos acerca das obras (pictóricas ou literárias) de seus contemporâneos. Muitos desses textos eram publicados nos mesmos jornais onde se liam seus folhetins. Apenas o Dumas conteur interessava?

Senti falta dos textos mais jornalísticos de Dumas, tanto no Brasil quanto em Portugal, que são muitos e, na maior parte das vezes, publicados em jornais fundados por ele. Talvez por se tratar de jornais de menor circulação, parece não terem chegado aos dois países lusófonos.

Nada encontrei também - nos dois países - dos textos biográficos que Dumas dedicava às figuras de destaque da sua geração, tais como: o grande ator Talma, a atriz Marie Dorval (escrito para angariar fundos para a construção de sua lápide) e tantos outros. Nem mesmo as causeries Grands hommes en robe de chambre, que fizeram tanto sucesso na França, apareceram nos levantamentos. Mesmo os textos dedicados à escritura do eu são raros, salvos os récits de voyage.

Depreendo, com mais segurança no caso das traduções portuguesas, bem mais organizadas graças ao trabalho de António Gonçalves Rodrigues do que no caso do Brasil, onde ainda há muito a ser feito, que o Alexandre Dumas que foi traduzido e mais bem assimilado nos Oitocentos foi o romancista, o contador de casos. 
Maria Lúcia

Dias Mendes

Ainda faltam muitos dados para concluir o mapeamento das traduções de Dumas no Brasil oitocentista. Mas talvez seja difícil superar a cifra de traduções portuguesas. A partir do levantamento feito por António Gonçalves Rodrigues em A tradução em Portugal, Alexandre Dumas foi o autor francês mais traduzido da década de 1850: de 1851 a 1860, foram lançadas nove traduções de romances de Victor Hugo, 16 de Émile Souvestre, 32 de Eugène Sue e o espantoso total de 109(!) de Alexandre Dumas.

No Brasil, temos à mesma época o sucesso da obra Dieu dispose, que aparece como o terceiro romance mais consultado na Biblioteca Nacional do Rio de Janeiro (entre os anos 1849-1856). Obra traduzida em Portugal no mesmo ano em que foi publicada em francês (1851) e publicada no Jornal do Commercio de setembro de 1851 a março de 1852, foi a mais pedida em 1854 (13 consultas), a terceira mais pedida em 1855 (12 consultas) e, em 1856, voltou a ser o romance mais consultado nessa biblioteca (26 solicitações) (ROCHA, 2011). Um sucesso que manteve o título nos anúncios do Jornal do Commercio.

O jornal, concorrente do livro por muitas vezes ser mais barato, tornou-se também uma espécie de suporte na divulgação das obras literárias, publicando as obras (que depois são transformadas em livros), trazendo anúncios de novidades à venda, comentando os lançamentos. Os anúncios das livrarias no Jornal do Commercio refletem também uma outra particularidade do mercado livreiro na cidade do Rio de Janeiro: a circulação concomitante de livros em português e nas línguas em que foram escritos. Nos anúncios das obras à venda de Alexandre Dumas em apenas dois anos, percebemos que era oferecido um número importante de obras em francês (Quadro 1):

\begin{tabular}{|l|l|}
\hline \multicolumn{1}{|c|}{1857} & \multicolumn{1}{|c|}{1858} \\
\hline Número de obras de Dumas anunciadas: 33 & Número de obras de Dumas anunciadas: 34 \\
Em francês: 12 & Em francês: 21 \\
Indefinível: 1 (El Salteador) & Indefinível: 1 (Urbano Grandier) \\
Em português: 20 & Em português: 12 \\
\hline
\end{tabular}

Quadro 1 - Número de obras de Dumas

Fonte: Müller (2012).

A simultaneidade de edições se confirma, e podemos afirmar que havia, no Brasil, a coexistência de livros e jornais impressos nos três países envolvidos nesse circuito da obra dumasiana. E ainda há a possibi- 
lidade de um "ir e vir", como dizia Marlyse Meyer (1996), entre folhetins publicados no Brasil e levados a Portugal; há o caso mesmo de uma edição portuguesa do Comte de Monte-Cristo publicada em livro a partir da tradução brasileira de Emilio Zaluar, que fora publicada no Correio Mercantil. Como sugere Ernesto Rodrigues: “Por elaborar está o estudo da presença, não raro pirateada, de folhetins em curso de publicação imediatamente e tempos das dados na Imprensa Brasileira, em que chegava a haver contrabando de granéis." (RODRIGUES, 1998, p. 245). Mais um ponto a esclarecer.

Muito ainda há por fazer em relação ao levantamento das publicações das obras de Alexandre Dumas, assim como em relação a outros autores românticos de sucesso (sobretudo aqueles que Marlyse Meyer traduções de Alexandre

Dumas em Portugal e no Brasil chamava de "segundo time"), mas já podemos delinear que o exame da circulação e das rotas das obras literárias durante o século XIX pode surpreender. $O$ trânsito dessas obras foi muito mais intenso do que talvez supomos, e as trajetórias, menos óbvias.

\section{Referências}

ABREU, Márcia (Org.). Trajetórias do romance: circulação, leitura e escrita nos séculos XVIII e XIX. São Paulo: Fapesp; Campinas: Mercado de Letras, 2008.

CANDIDO, Antonio. Formação da Literatura Brasileira: momentos decisivos. São Paulo: Fapesp; Rio de Janeiro: Ouro sobre Azul, 2009.

DUMAS, Alexandre. Mes mémoires. Paris: Robert Laffont, 1989. Tomo 2.

FRANÇA, José-Augusto. Duas notas sobre Alexandre Dumas em Portugal. In: Antes da Playstations: 200 anos de aventuras em Portugal. Lisboa: Biblioteca Nacional, 2003. p. 63-70.

HALLEWELL, Laurence. o livro no Brasil. São Paulo: T. A. Queiróz: Edusp, 1985.

LYONS, Martyn. Les best-sellers. In: CHARTIER, Roger; MARTIN, Henri-Jean. Histoire de l'édition française. Paris: Fayard/Promodis, 1990. p. 409-448. 
MEYER, Marlyse M. Folhetim: uma história. São Paulo: Companhia das Letras, 1996.

MÜLLER, Andréa Correa Paraiso. Do romance imoral a obra-prima: trajetórias de Madame Bovary. 2012. Tese (Doutorado em Teoria e História Literária)-Instituto de Estudos da Linguagem, Universidade Estadual de Campinas, Campinas, 2012.

RÊGO, Manuela e Miguel Castelo-Branco (coord). Antes das

Maria Lúcia

Dias Mendes Playstations: 200 anos do romance de aventuras em Portugal. Biblioteca Nacional: Lisboa, 2003.

RIBEIRO, Manuela Tavares. Livros e leituras no século XIX. Revista de História das Ideias, Universidade de Coimbra, Instituto de História e Teoria das Ideias, v. 20 (Livro e Leitura), p.187-227, 1999. Disponível em: <http://rhi.fl.uc.pt/vol/20>. Acesso em: 15 fev. 2011.

ROCHA, Débora Cristina Bondance. Bibliotheca Nacional e Pública do Rio de Janeiro: um ambiente para leitores e leituras de romance (1833-1856). 2011. 347 f. Dissertação (Mestrado em Teoria e História Literária)-Instituto de Estudos da Linguagem, da Universidade Estadual de Campinas, Campinas, 2011.

RODRIGUES, Antonio. A tradução em Portugal. Lisboa: Ministério da Educação: Instituto de Cultura e Língua Portuguesa, 1992. v. 2 (1835-1850) e v. 3 (1851-1870).

RODRIGUES, Ernesto. Mágico folhetim: literatura e jornalismo em Portugal. Lisboa: Editorial Notícias, 1998.

. Cultura Literária Oitocentista. Porto: Lello Editores, 1999.

SANTOS, Ana Clara. La pratique de la traduction théâtrale ou les voies de la création dramaturgique sur la scène portugaise XIX ${ }^{\mathrm{e}}$ siècle. Artigos, Instituto Camões. Disponível em: <http://cvc. instituto-camoes.pt/bdc/artigos/anaclarasantos.pdf>. Acesso em: 9 mar. 2008. 
SOBREIRA, Luis. Uma imagem do campo literário português no período romântico através dos best-sellers produzidos entre 1840 e 1860 . In: CONGRESSO INTERNACIONAL DA ASSOCIAÇÃO PORTUGUESA DE LITERATURA COMPARADA, 4., 2001, Évora. Anais... Évora, 2001. Disponível em: <http://www.eventos.uevora.pt/comparada/VolumeI/ Trajetórias UMA\%20IMAGEM\%20DO\%20CAMPO\%20LITERARIO\%20PORTUGUES. pdf. p.2>. Acesso em: 15 fev. 2011.

THÉRENTY, Marie-Éve. La littérature au quotidien: poétiques journalistiques au XIX ${ }^{\mathrm{e}}$ siècle. Paris: Seuil, 2007.

\section{Outras fontes} e tempos das traduções de Alexandre Dumas em Portugal e no Brasil

Biblioteca Nacional de Portugal. Disponível em: <http://www.bnportugal.pt>.

Catálogo Biblioteca Fluminense, 1866.

Jornal do Commercio; Diário do Rio de Janeiro; Correio Mercantil; O Mercantil. Disponíveis em: <http://www.hemerotecadigital.bn.br>.

Real Gabinete de Leitura (acervo).

World Catalog. Disponível em: <http://www.worldcat.org>.

Referências das publicações das obras de Alexandre Dumas: SCHOPP, Claude. Bibliographie. In: Mês Mémoires. Paris: Robert Laffont, 1989.

Em Portugal, a maior parte das referências às traduções foi retirada da obra de Antonio Gonçalves Rodrigues. 


\section{Anexo A - Publicações de Alexandre Dumas (França - Portugal - Brasil)}

Maria Lúcia

Dias Mendes

\begin{tabular}{|c|c|c|c|}
\hline \multicolumn{4}{|c|}{$\begin{array}{c}\text { Publicações de Alexandre Dumas } \\
\text { França - Portugal - Brasil }\end{array}$} \\
\hline Obra & França & Portugal & Brasil \\
\hline 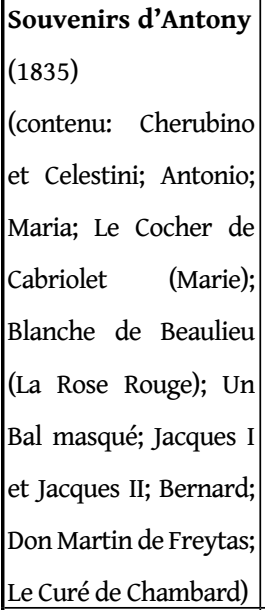 & $\begin{array}{l}\text { Dumont, } 1841 \\
\text { (édité avec D.Martin } \\
\text { de Freytas e Praxède) }\end{array}$ & $\begin{array}{l}\text { Martin de Freitas. } \\
\text { a) Novella tirada de } \\
\text { um facto celebre da } \\
\text { Historia Portuguesa e } \\
\text { posta em vulgar por } \\
\text { TC. Porto, t da Revista, } \\
\text { in-8, } 58 \text { p. 1841. (AR) } \\
\text { b) Lisboa: Imp. Her- } \\
\text { menegildo Pires Ma- } \\
\text { rinho, 1855. (BNP) }\end{array}$ & $\begin{array}{l}\text { Martin de Freitas. } \\
{[\text { S.l1]: [s.n.], 1841. (RG) }} \\
{[2 \text { anúncios no Jor- }} \\
\text { nal do Commercio em } \\
1840 ; 2 \text { em } 1842 ; 5 \text { em } \\
1843(\mathrm{RM})]\end{array}$ \\
\hline $\begin{array}{l}\text { Pascal Bruno } \\
1837\end{array}$ & $\begin{array}{l}\text { La Presse } 23 \text { jan-3 fév } \\
1837 / \\
\text { Dumont, } 1837\end{array}$ & $\begin{array}{l}\text { Pascal Bruno. Ro- } \\
\text { mance historico de } \\
\text { Mr. Alex. Dumas. } \\
\text { Traduzido por V. J. A. } \\
\text { J. Lisboa, 1841, in-8. } \\
\text { (CBF) e (AR) [ref. In: } \\
\text { “Um quarto de hora } \\
\text { de leitura” n.1, 10pp.] } \\
\text { b) versão do fr. Por José } \\
\text { Melchiades Ferreira } \\
\text { dos Santos. A União, } \\
\text { Lisboa, } 4 \text { out 1849. }\end{array}$ & 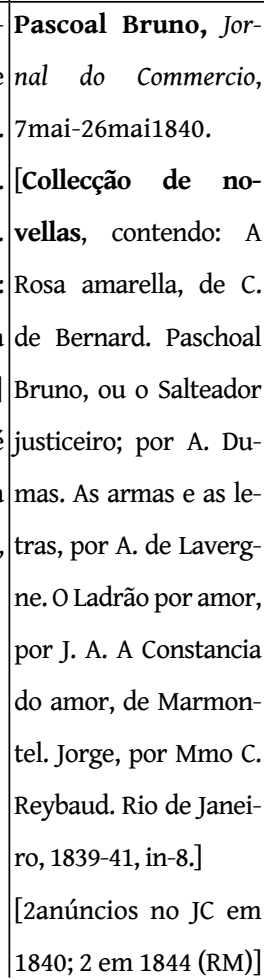 \\
\hline
\end{tabular}


(Conclusão)

\begin{tabular}{|c|c|c|c|}
\hline \multicolumn{4}{|c|}{$\begin{array}{c}\text { Publicações de Alexandre Dumas } \\
\text { França - Portugal - Brasil }\end{array}$} \\
\hline $\begin{array}{l}\text { Le Capitaine Paul, } \\
1838\end{array}$ & $\begin{array}{l}\text { Le Siècle (30 mai-23 } \\
\text { juin 1838) }\end{array}$ & $\begin{array}{l}\text { o Capitão Paulo, ro- } \\
\text { mance de Alexandre } \\
\text { Dumas, traduzido por } \\
\text { M. A. da S. Nova edi- } \\
\text { ção. Lisboa, } 18182 \text { vol. } \\
\text { in-8.(CBF) edição pro- } \\
\text { vavelmente igual a ci- } \\
\text { tada por AR: trad. Mi- } \\
\text { guel Antonio da Silva, } \\
\text { 2vol in-8, Lisboa, 1841. } \\
\text { o Capitão Paulo, } \\
\text { drama em } 5 \text { atos, } \\
\text { 1843. Lb.p.349-381. }\end{array}$ & $\begin{array}{l}\text { o Capitão Paulo, } \\
\text { Jornal do Commercio, } \\
31 \text { out-27 nov } 1838 . \\
\text { [5 em } 1838,19 \text { anúncios } \\
\text { em } 1839 ; 4 \text { anúncios no } \\
\text { JC em } 1841 ; 12 \text { em } 1843 ; \\
1 \text { em } 1844(\mathrm{RM})] \\
50 \text { x de } 183911844\end{array}$ \\
\hline
\end{tabular}

Trajetórias

e tempos das traduções de

Alexandre

Dumas em

Portugal e no

Brasil

\section{Anexo B - Publicações de Alexandre Dumas (França - Brasil)}

\section{(Continua)}

\begin{tabular}{|c|c|}
\hline \multicolumn{2}{|c|}{ Publicações França - Brasil } \\
\hline $\begin{array}{l}\text { Ainsi soit-il ou Madame de Chamblay, } \\
\text { Le Monte-Cristo, } 19 \text { nov - } 8 \text { juil } 1858\end{array}$ & $\begin{array}{l}\text { Madame de Chamblay, Diário do Rio de } \\
\text { Janeiro, } 1865 .\end{array}$ \\
\hline $\begin{array}{l}\text { Le chasseur de Sauvagine } 15 \text { nov } 1857 . \\
\text { A.Cadot } 1858\end{array}$ & $\begin{array}{l}\text { o Caçador de Selvagina, } \\
\text { a) Jornal do Commercio, } 28 \text { mar-8 mai 1858/ } \\
\text { b) Rio Grande: Tipografia Antonio Este- } \\
\text { vão, } 1857 . \Omega \text { [Biblioteca do Rio Grande] }\end{array}$ \\
\hline $\begin{array}{l}\text { Mémoires d'um policeman. Esquisses } \\
\text { des moeurs anglaises. } \\
\text { Le Siècle } 30 \text { avril-21 mai } 1858 \\
\text { A.Cadot, } 1859\end{array}$ & $\begin{array}{l}\text { Esboços de costumes ingleses: Memórias } \\
\text { de um policeman, Correio Mercantil, } 1858 \text {. } \\
\text { Memórias de um policeman. Rio Grande: } \\
\text { Tipografia Antonio Estevão, } 1858 . \Omega\end{array}$ \\
\hline
\end{tabular}


(Continuação)

\begin{tabular}{|c|c|c|}
\hline \multirow[b]{2}{*}{$\begin{array}{l}\text { Maria Lúcia } \\
\text { Dias Mendes }\end{array}$} & \multicolumn{2}{|c|}{ Publicações França - Brasil } \\
\hline & $\begin{array}{l}\text { Maître Adam, le Calabrais } \\
\text { Le Siècle } 26 \text { fév-14 mars } 1839 \\
\text { Auguste Ozanne, } 1839\end{array}$ & $\begin{array}{l}\text { Mestre Adam, o calabrês, JC, } 04 \text { out-2 } \\
\text { 8out } 1839 \text {. } \\
\text { [Colecção de novellas, contendo: Mestre } \\
\text { Adam o Calabrez por A. Dumas. Os Dois Car- } \\
\text { rascos, por Balzac. A Casa emparedada, por } \\
\text { E. Bertliet. Uma desgraça completa, por F. } \\
\text { Soulié. Os cincoenta annos ou o velho namo- } \\
\text { rado, por C. de Bernard. Gabrielli k ou um } \\
\text { ardil do amor. Rio de Janeiro, 1839-42. in-8.] } \\
\text { [4 anúncios no Jornal do Commercio em } \\
1839 \text { (RM)] }\end{array}$ \\
\hline \multirow{5}{*}{$\overline{154}$} & $\begin{array}{l}\text { Orthon, l'archer } \\
\text { Le Siécle, } 25 \text { déc1838-24 jan.1839 }\end{array}$ & $\begin{array}{l}\text { Othon, o arqueiro - Crônica das margens } \\
\text { do Reno, Jornal do Commercio, } 5 \text { juil-28 juil } 1839 \\
\text { [3 anúncios no Jornal do Commercio em } \\
\text { 1839; } 3 \text { em 1840; } 2 \text { em1844 (RM)] }\end{array}$ \\
\hline & $\begin{array}{l}\text { Ascanio } \\
\text { Le Siècle, } 31 \text { juil-4 oct } 1843 \\
\text { Petition, } 1844\end{array}$ & $\begin{array}{l}\text { Ascânio, ou A corte de Franscisco I: ro- } \\
\text { mance histórico. Rio Grande: Typ. do Co- } \\
\text { mercial, } 1859 . \Omega \\
\text { [anunciada no Jornal do Commercio em } 1857 \\
\text { em português!!!!] (AM) }\end{array}$ \\
\hline & $\begin{array}{l}\text { La Chasse au Chastre (Le Midi de la France) } \\
\text { La Presse } 21 \text { jan- } 31 \text { jan } 1841\end{array}$ & $\begin{array}{l}\text { A Caçada do chastre, Diário do Rio de Ja- } \\
\text { neiro, } 1842 \text {. }\end{array}$ \\
\hline & $\begin{array}{l}\text { Une séance de magnétisme chez M. A. D. (?) } \\
\text { La Presse, } 16 \text { sept-17 oct } 1847 \\
\text { Bric-à-brac /À propos d'art et de cuisine } 1861 \\
\text { La plupart de ces textes sont parus entre } \\
1853 \text { et } 1858 \text { dans les journaux auxquels } \\
\text { Dumas collaborait (Le pays, La presse, Le } \\
\text { mousquetaire et Le Monte-Cristo) avant } \\
\text { d'être regroupés dans deux volumes aux } \\
\text { éditions Michel Lévy. }\end{array}$ & $\begin{array}{l}\text { Memórias de Alexandre Dumas. O mag- } \\
\text { netismo animal. (Extrato de La Presse). } \\
\text { Rio Grande: Tipografia do Rio-Grandense, } \\
\text { de B. Berlink, 1856. } \Omega \text { BRG }\end{array}$ \\
\hline & $\begin{array}{l}\text { Le Conte Hermann } \\
\text { Drama 5a, } \\
22 \text { nov1849 Théâtre-Historique } \\
\text { L'Ordre }\end{array}$ & $\begin{array}{l}\text { O conde Hermano. Santos (SP): Typogra- } \\
\text { phia Commercial de G. Delius, } 1852 \text { (RG) }\end{array}$ \\
\hline
\end{tabular}




\begin{tabular}{|c|c|}
\hline \multicolumn{2}{|c|}{ Publicações França - Brasil } \\
\hline $\begin{array}{l}\text { Montevideo ou une nouvelle Troie } \\
\text { Le mois, } 1^{\mathrm{er}} \text { jan- } 1^{\mathrm{er}} \text { fév1850, l'Imprimerie de } \\
\text { Napoléon Chaix et Cie. } 1850 .\end{array}$ & $\begin{array}{l}\text { Montevideo. In Rio Grandense, de } 15 \text { mai a } \\
12 \text { jun } 1851 \Omega\end{array}$ \\
\hline $\begin{array}{l}\text { Ingénue. } \\
\text { Le Siècle, } 30 \text { août-8déc } 1851\end{array}$ & Ingênua, Diário do Rio de \\
\hline $\begin{array}{l}\text { Dieu et Diable (Conscience l'innocent) } \\
\text { Le Pays, } 26 \text { fév-7 avril } 1852 \\
\text { A. Cadot, } 1853\end{array}$ & $\begin{array}{l}\text { Deus e diabo, Jornal do Commercio, } 18 \text { set- } \\
19 \text { dez } 1852 . \\
\text { “Deus e o Diabo". In Rio Grandense, de } 25 \\
\text { dez } 1852 \text { a } 26 \text { jan } 1853 \Omega\end{array}$ \\
\hline $\begin{array}{l}\text { Moullah-Nour (recueil), } \\
\text { Moullah-Nour. Bruxelles: Méline, Cans et } \\
\text { Cie., } 1853\end{array}$ & $\begin{array}{l}\text { Moullah-Nour, O João diabo, Diário do Rio } \\
\text { de Janeiro, 1860/1861. }\end{array}$ \\
\hline $\begin{array}{l}\text { Le page du Duc de Savoie } \\
\text { Le Constitutionnel, } 20 \text { sept.1854-19 janv.1855 } \\
\text { A.Cadot }\end{array}$ & $\begin{array}{l}\text { O Pajem do duque de Sabóia, Jornal do } \\
\text { Commercio, } 8 \text { dez-29 dez, 1854/ } 1 \text { jan-2 fev, } \\
1855 \text { / } 5 \text { abr-9 mai } 1855\end{array}$ \\
\hline $\begin{array}{l}\text { Les compagnons de Jéhu [Les blancs et } \\
\text { les bleus; Chevalier de Sainte-Hermine] } \\
\text { Journal pour tous; } 20 \text { déc } 1856-4 \text { avril } 1857\end{array}$ & $\begin{array}{l}\text { Os companheiros de Jehu. [S.l]: [s.n.], } \\
1861(\mathrm{RG}) \\
\text { [Deve ser uma edição brasileira, pois não } \\
\text { consta do (AR)] }\end{array}$ \\
\hline $\begin{array}{l}\text { La Frégate. L'Espérance } \\
\text { (Marlinski). (La princesse Flora). } \\
\text { Le Monte-Cristo, } 17 \text { mars-9 juin } \\
\text { A.Cadot, } 1859\end{array}$ & $\begin{array}{l}\text { A Fragata esperança, Diário do Rio de Ja- } \\
\text { neiro, } 1860 .\end{array}$ \\
\hline $\begin{array}{l}\text { L' Horoscope } 1858 \\
\text { [não encontrei referências mais exatas da } \\
\text { publicação] }\end{array}$ & $\begin{array}{l}\text { O Horóscopo, Jornal do Commercio, } 30 \text { dez- } \\
31 \mathrm{dez}, 1858 / 01 \text { jan-27 fev } 1859 \text {. }\end{array}$ \\
\hline
\end{tabular}

Trajetórias

e tempos das traduções de

Alexandre

Dumas em

Portugal e no

Brasil 